\title{
Ultrastructural study of a case of epidermolysis bullosa simplex superficialis (EBSS)
}

\author{
A.P. Alves de Matos*, C. Gouveia**, A.B. Sousa*** and A. Afonso**** \\ *Anatomia Patológica, Centro Hospitalar de Lisboa Central - HCC, Rua da Beneficência 8, 1069-166 Lisboa, \\ Portugal; Centro de Estudos do Ambiente e do Mar (CESAM/FCUL) - Faculdade de Ciências da Universidade \\ de Lisboa and Centro de Investigação Interdisciplinar Egas Moniz (CiiEM), Quinta da Granja, Monte de \\ Caparica, 2829-511 Caparica, Portugal \\ **Hospital de Santa Maria-CHLN, Serviço de Dermatologia, Avenida Professor Egas Moniz \\ 1649-035 Lisboa, Portugal \\ ***Hospital de Santa Maria-CHLN, Serviço de Genética, Avenida Professor Egas Moniz \\ 1649-035 Lisboa, Portugal \\ ****Hospital Cuf Descobertas, Anatomia Patológica, R. Mário Botas 1998-018 Lisboa, Portugal
}

A very rare subset of Epidermolysis bullosa simplex (EBS), termed "EBS superficialis" (EBSS), has been described in two families. EBS superficialis is a rare autosomal dominant form of suprabasal EBS in which blistering arises just below the stratum corneum [1].

The original report of EBSS was subsequently questioned by genetic analysis of one of the families that identified a mutation in a collagen gene responsible for dystrophic epidermolysis bullosa (DEB), thus implying that this entity is in fact a variant of DEB [2]. Nonetheless, the existence of some form of EBSS can not be ruled out [1].

We performed a transmission electron microscopy study of a skin biopsy from a 36 year old woman suspect of having EBSS. A skin biopsy was sequentially fixed in 3\% glutaraldehyde in sodium cacodylate buffer $0.1 \mathrm{M} \mathrm{pH}$ 7.3, osmium tetroxide in the same buffer and uranyl acetate in acetate-acetic acid buffer $0.1 \mathrm{M} \mathrm{pH} 5$. Dehydration was performed in ethanol and embedding in an Epon-Araldite mixture. Thin sections contrasted with uranyl acetate and lead cytrate were observed and photographed in a JEOL 100SX electron microscope.

She had a few intact acral bullae in the neonatal period and superficial erosions and crusts in friction areas since then. Her one year-old boy, her older sister and the latter's adolescent son had the same clinical picture. The patient does not display any symptoms expected for DEB.

We found profound alterations of the structure of the outer layers of the epidermis. Degenerative changes were seen in the cells of the upper layers of the stratum spinosum. Nuclei are lost and flattened cells made mostly of compressed tonofilaments lay below a cleft that develops between the compressed cells and the granular cell layer (Fig. 1). The granular cell layer is very reduced and represented by a few damaged cells that stay attached to the stratum corneum (Fig. 2).

The alterations do not seem to be related to collagen defects, and in the reported case the cleft develops in the altered upper region of the prickle-cell layer, just below the granular layer.

References

1. Fine J-D., Orphanet Journal of Rare Diseases, 5:12, 2010

2. Martinez-Mir, A. et al., J. Invest. Dermatol., 118:547, 2002 


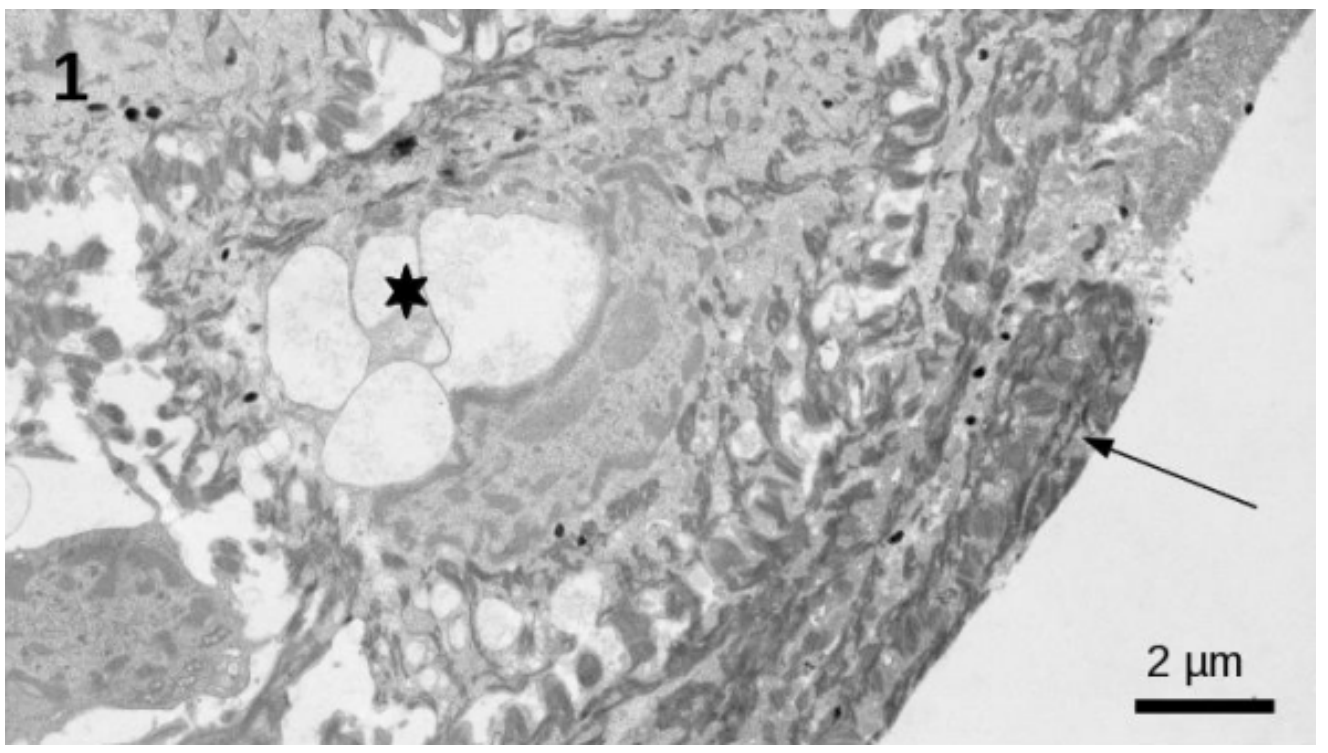

Fig. 1. Epidermis of affected skin. The stratum corneum and granular layer are absent. Degenerative changes are seen in the upper cells of the spinous layer $(*)$ and the most superficial cells form a flattened layer filled with packed tonofilaments $(\rightarrow)$.

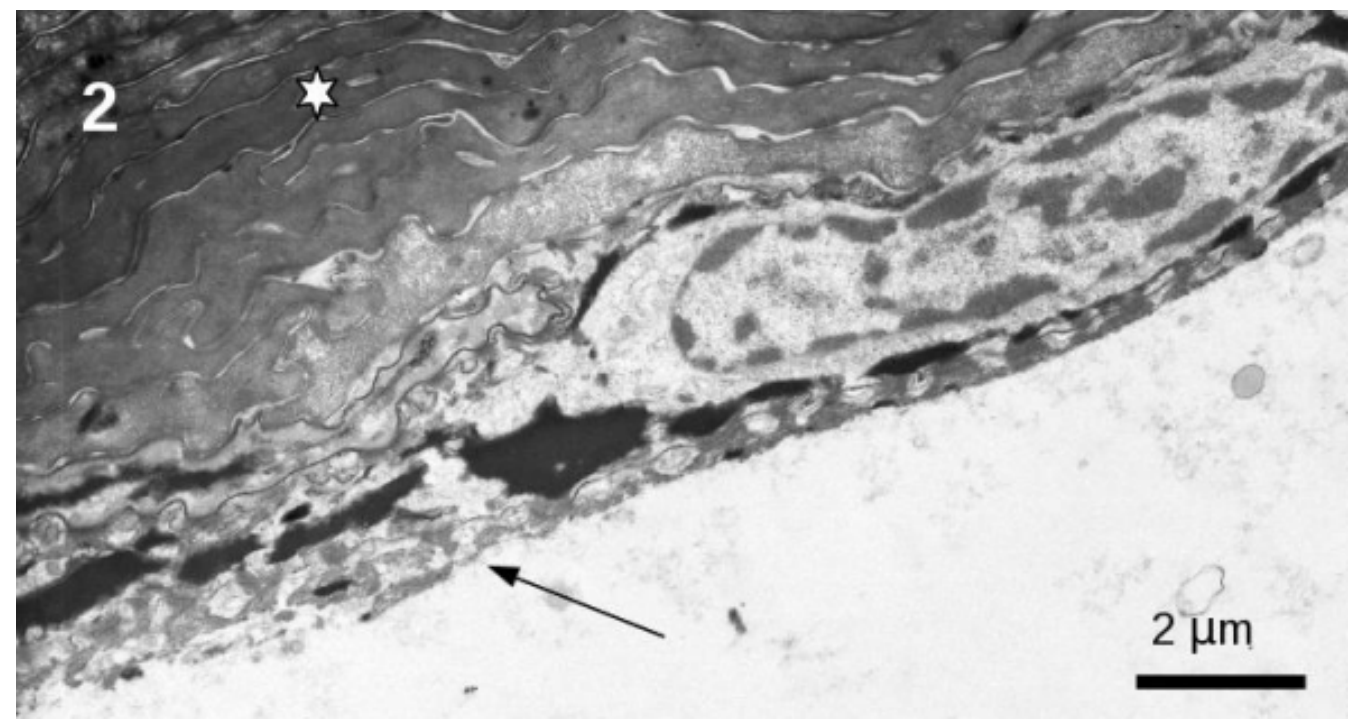

Fig. 2. Desquamated outer layers of the epidermis. The stratum corneum (*) and a single layer of flattened of granular cells can be observed. Tonofilament containing cell residues are attached to the exposed granular cell layer $(\rightarrow)$. 